\title{
Luchas memoriales y estrategias de poder de las derechas en América Latina hoy
}

\author{
Memorial struggles and power strategies \\ of the rights in Latin America today
}

\author{
Verónica Giordano \\ Docente e investigadora \\ UBA y CONICET \\ veronicaxgiordano@gmail.com \\ Código Orcid: https://orcid.org/0000-0001-7299-6984 \\ Gina Paola Rodríguez \\ Docente e investigadora \\ UNLPam y UBA \\ paolitarodriguez1789@gmail.com \\ Código Orcid: https://orcid.org/0000-0002-1702-3386
}

\begin{abstract}
Resumen
Recientemente han despuntado en América Latina fuerzas de derecha de distinto origen y tipo. En este artículo, se estudian cuatro países: Argentina, Brasil, Colombia y Perú. Los dos primeros corresponden a casos en los que las derechas se erigen en contraposición a los gobiernos denominados progresistas. Los otros dos corresponden a casos en los que las derechas se erigen en un sistema político con una fuerte continuidad de predominio de la derecha. Puesto que son escasos los análisis con perspectiva de conjunto, este artículo pretende hacer un aporte en esa dirección. El objetivo es analizar las estrategias no electorales de construcción y/o ejercicio del poder implementadas por las derechas actuales en torno a las luchas memoriales. Con base en la revisión de fuentes periodísticas y discursos de los referentes de las derechas nacionales, el presente artículo analiza de qué manera las derechas han procedido a la institución de lenguajes y a la definición de un campo de sentidos que disputan el significado del pasado reciente. A partir de una perspectiva comparada, se sostiene que en los cuatro casos el negacionismo ofrece un repertorio eficaz para esos grupos, que se valen de él en sus estrategias no electorales (además de las electorales) para la construcción de hegemonía en el nivel cultural.
\end{abstract}

\section{Palabras clave}

Derecha, estrategias no electorales, América Latina, memoria, negacionismo, hegemonía cultural.

Forma sugerida de citar: Giordano, V., y Rodríguez, G. (2019). Luchas memoriales y estrategias de poder de las derechas en América Latina hoy. Universitas, 31, pp. 19-36. 


\begin{abstract}
Recently, right-wing forces of different origins and types have sprung up in Latin America. In this article, four countries are studied: Argentina, Brazil, Colombia and Peru. The first two correspond to cases in which the right-wing groups stand in opposition to the so-called progressive governments. The other two correspond to cases in which they stand in a political system with a strong continuity of predominance of right-wing forces. Since there are few studies with an overall perspective, this article seeks to make a contribution in that direction. The objective is to analyze the non-electoral strategies of construction and/ or exercise of power implemented by the right-wing groups around the memorial struggles. Based on the review of journalistic sources and speeches of the national right-wing referents, this article analyzes how current right-wing groups have proceeded to the institution of languages and the definition of a field of meanings that dispute the meaning of the recent past. From a comparative perspective, it is argued that in all four cases negationism offers an effective repertoire for these groups, which is used in their nonelectoral (as well as electoral) strategies for building hegemony at the cultural level.
\end{abstract}

\title{
Keywords
}

Right, non-electoral strategies, Latin America, memory, negationism, cultural hegemony.

\section{Introducción}

Recientemente han despuntado en América Latina fuerzas de derecha de distinto origen y tipo (Giordano, 2019; Rodríguez, 2019). Mientras en Argentina y Brasil el arribo de gobiernos de derecha se relaciona directamente con el agotamiento de los procesos reformistas previos, en países como Colombia y Perú, las derechas actuales se inscriben en un sistema político de prolongado predominio de fuerzas de ese signo. No obstante, estas diferencias, las derechas de los cuatro países tienen en común el despliegue de estrategias dirigidas a disputar el sentido del pasado reciente en torno a las dictaduras (Argentina y Brasil) y el conflicto armado (Perú y Colombia). Las luchas memoriales ocupan un lugar central en los temas que informan esas estrategias no electorales, cuyo objetivo es operar en el nivel de la sociedad civil vía medios de comunicación, organizaciones y fundaciones y acciones directas (Eaton, 2014). En el plano de la memoria pública, este conjunto de acciones apunta a la politización de temas afines a un ideario autoritario y conservador, a través de 
la construcción de un sentido común simplificador y polarizante que tiende a negar un pasado traumático (negacionismo/revisionismo histórico). Más allá de las intensidades diversas con que esas estrategias se han implementado en cada uno de los escenarios nacionales, en todos los casos el pasado reciente se ha constituido en el objeto privilegiado de las "luchas memoriales" en el campo político (i.e. pujas entre diversos actores por constituir su interpretación en la representación hegemónica de lo acontecido, Jelin, 2002).

La necesidad de analizar los usos políticos del pasado apremia en tiempos en los que desde distintos ámbitos se propone hacer de la memoria histórica un "camino superado" para "mirar al futuro" y encontrar sendas de "reconciliación nacional" o "cerrar definitivamente etapas dolorosas" (Ricoeur, 2010). En la retórica de las fuerzas políticas de derecha en Argentina, Brasil, Colombia y Perú convergen, sin mayores contradicciones, la explotación y radicalización de las escisiones maestras que marcaron la violencia política y el negacionismo latente o manifiesto de la responsabilidad estatal y civil en la comisión de crímenes contra la comunidad nacional. Esto remite, como resalta Grimson (2007, p. 12):

Una condición básica de cualquier proyecto hegemónico (...) instituir los lenguajes de la disputa social, definir el campo de sentidos donde se desarrolla el conflicto social, estipular con eficacia cuáles son las acciones, reclamos $\mathrm{y}$ repertorios potencialmente eficaces en una etapa determinada.

Con base en la revisión de fuentes periodísticas y discursos de los referentes de las derechas nacionales, el presente artículo analiza de qué manera los grupos de ese signo ideológico han procedido a la institución de lenguajes y a la definición de un campo de sentidos que disputan el significado del pasado reciente. Desde una perspectiva comparativa, sostenemos que el negacionismo es un repertorio eficaz para las derechas actuales, que se valen de él en sus estrategias no electorales (además de las electorales) para la construcción de hegemonía en el nivel cultural.

\section{Argentina: "diálogo" y "reconciliación"}

Argentina fue el único país que tras la caída de las "dictaduras institucionales de las Fuerzas Armadas" (Ansaldi \& Giordano, 2012) inició el enjuiciamiento a los militares involucrados en delitos de lesa humanidad. 
Esta iniciativa quedó interrumpida por las leyes de Obediencia debida y Punto Final (1987) bajo el Gobierno de Raúl Alfonsín y luego por el Indulto (1989-1990) otorgado por el presidente Carlos Menem. Sin embargo, en 2003 el Gobierno de Néstor Kirchner retomó la senda jurídica, incluso avanzando, en los años posteriores, en el enjuiciamiento a civiles que habían actuado en complicidad con el régimen de la dictadura en la comisión de delitos económicos y de lesa humanidad.

La publicación en 1986 del informe elaborado por la Comisión Nacional de Personas Desaparecidas (CONADEP), publicado bajo el título Nunca Más, inauguró un "régimen de memoria" (Crenzel, 2008). Allí, se estableció la cifra de 9000 personas desaparecidas bajo la última dictadura. Fundados en evidencias adicionales, los organismos de DDHH asumieron la cifra de 30000 . Y sobre esta base se edificó el consenso acerca de la cantidad de víctimas del terrorismo de Estado y un "relato canónico" acerca del pasado reciente (Crenzel, 2008). Si bien hubo intentos de desestabilizar ese consenso en momentos previos, el mismo comenzó a resquebrajarse más seriamente a partir de la llegada al Poder Ejecutivo Nacional del PRO en la alianza Cambiemos en 2015.

Funcionarios del Gobierno y hasta el propio presidente Mauricio Macri polemizaron acerca de la cifra de 30000 vs. 9000 ("Mauricio Macri”, 2016). Y así el negacionismo se volvió estatal (antes la controversia en torno al número se había planteado, claro está, pero no desde el poder del Estado). Un episodio más reciente de negacionismo a voces se produjo en la Feria del Libro 2019, cuando se presentó el libro de Jorge Di Pascuale, exmilitar represor condenado por el asesinato de la hija de la titular de las abuelas de Plaza de Mayo, Estela de Carlotto. Bajo el título Crónica de una guerra negada, Di Pascuale (2019) reúne tres volúmenes de claro espíritu negacionista, en los que aspira a "echar luz sobre años trágicos, durante los cuales nuestra Patria sufrió una guerra revolucionaria" y explica el proceso ocurrido entre 1976 y 1982 como "la victoria de las Fuerzas Legales sobre las milicias irregulares". El panel de presentación estuvo integrado por militares retirados y por el periodista Ceferino Reato, en una sala llena de familiares de represores investigados, imputados y condenados por delitos de lesa humanidad cometidos durante la última dictadura ("Carlotto", 2019).

Este negacionismo encastra con otro elemento del que las derechas son portadoras: "el utopismo de la democracia dialogante" (Hinkelammert, 1988). Una figura clave para entender la apropiación de este elemento y la 
promoción del revisionismo histórico en las filas del PRO es Pablo Avelluto (Saferstein, 2017). Entre 2005 y 2012, Avelluto fue Director Editorial de la Región Sur de Random House Mondadori Argentina, que administra el sello Sudamericana. En 2012, entró de lleno al mundo de la política de la mano del PRO: fue coordinador general del Sistema de Medios públicos en el Gobierno de la Ciudad de Buenos Aires y luego Ministro de Cultura de la Nación (actualmente rebajado al rango de Secretaría). A instancias de su gestión, en 2015 se publicó el libro El diálogo, editado por el sello Sudamericana y del cual Avelluto fue editor y colaboró en la escritura (Fernández Meijide \& Leis, 2015). Se trata de una conversación entre Héctor Leis (que integró las filas de Montoneros) y Graciela Fernández Meijide (madre de un desaparecido, integrante de la CONADEP y miembro de la Asamblea Permanente de Derechos Humanos, APDH, y devenida dirigente política en los años noventa). En el libro (y en el documental que se filmó a partir del mismo material), la noción de "diálogo" remite a una conversación entre partes que lejos de ser antagónicas muestran coincidencias. Se trata de una noción de diálogo que es constitutiva de la identidad Cambiemos, y que se observa en tantas otras instancias, tal como señalan Goldentul y Saferstein (2019).

La comunidad de ideas que estructuró al "mundo PRO" (Vommaro, Morresi, \& Belloti, 2015) en su escalada hacia el Estado nacional se construyó sobre la base de una estrecha relación entre emprendimientos editoriales (fundamentalmente, pero no exclusivamente, de la Editorial Sudamericana) y la Fundación Pensar, el think tank del PRO (Giordano \& Soler, 2016 y Giordano, 2017). En 2015 Iván Petrella, por entonces legislador de la Ciudad de Buenos Aires y Director de esa Fundación, publicó Que se metan todos, también bajo el sello Sudamericana (Petrella, 2015). En él se observa otra veta del "utopismo de la democracia dialogante": el borramiento de los conflictos. En este caso, a través de la promoción de la noción de "reconciliación", recuperando el modelo de Comisión de la Verdad de Sudáfrica. En un capítulo, Petrella refiere específicamente a una posible aplicación en Argentina del modelo sudafricano de reconciliación como alternativa al modelo de Justicia implementado por los gobiernos anteriores, promoviendo la vía de la amnistía para alcanzar la Verdad.

A partir de su acceso al poder del Estado, el PRO (en la alianza Cambiemos) ha intentado implementar medidas en línea con el negacionismo que ya era parte de su repertorio de ideas. Así, ha buscado reconfigurar el campo de la memoria en una operación de sentido por la cual las diferencias históricas 
se suspenden en pos de una vocación de coincidencia. En el plano de la retórica, por ejemplo, en la ocasión de la conmemoración del golpe el 24 de marzo de 2017, el secretario de Derechos Humanos Claudio Avruj afirmó: "los derechos humanos son para todos" ("El discurso PRO", 2017). En el plano legal, el PRO ha hecho también algunos intentos. El más sonado fue un fallo de la Corte Suprema de Justicia de la Nación del 3 de mayo de 2017 que admitía el cómputo del " $2 \times 1$ " en crímenes de lesa humanidad (computar doble el tiempo en condición de detenidos antes de contar con una sentencia firme, un beneficio que había sido estipulado en 1994 para los delitos comunes y que fue derogado en 2001). La medida fue rechazada y pocos días después el Congreso sancionó la ley 27.362 que estableció taxativamente que no podía aplicarse ese beneficio en casos de delitos de lesa humanidad y que por otra parte reafirmaba la validez de la medida para el período 1994-2001. Si bien hubo marcha atrás, no puede soslayarse el alcance de la voluntad negacionista del Gobierno, que busca afianzarse no sólo en la retórica sino también en las leyes.

\section{Brasil: "contra el comunismo"}

A diferencia de Argentina, en Brasil hubo una Ley de Amnistía dictada en 1979, durante la dictadura. Si bien inicialmente esta ley recogió las demandas de los movimientos de resistencia a la dictadura que pedían amnistía para los presos políticos, enseguida fue utilizada por las FFAA para extenderla a los perpetradores de crímenes cometidos bajo el régimen instaurado en 1964, interpretando los términos "crímenes políticos o conexos" en su favor. Otra diferencia significativa es que en Brasil no hubo una Comisión de Verdad sino hasta 2012, cuando bajo el gobierno de Dilma Rousseff se instituyó la Comisión Nacional de la Verdad de Brasil (CNV).

La CNV estableció que entre 1964 y 1985 hubo más de 434 asesinatos políticos o desaparecidos, más de 10000 torturados, y unos 8000 indígenas asesinados para concretar planes de infraestructura y agricultura en la región amazónica. Las graves violaciones de derechos humanos ocurridas en el período investigado, concluye la $\mathrm{CNV}$, "resultaron de una acción generalizada y sistemática del Estado, configurando crímenes contra la humanidad" que fueron "protagonizados por las Fuerzas Armadas cuyo ejercicio implicó cadenas de mando originadas en los gabinetes de los presidentes y ministros militares" (CNV, 2014). 
El informe de la CNV se publicó un año antes de la destitución de Dilma y el giro a la derecha que se inició con el mandato de Michel Temer dejó muy debilitada a la iniciativa. En efecto, no obstante, la exhortación de la CNV para que las Fuerzas Armadas reconozcan su responsabilidad institucional, la tendencia reciente en sendos sectores civiles y castrenses está más próxima a la apología de la dictadura. La llegada del excapitán Jair Bolsonaro a la presidencia en 2019 ha corrido en paralelo con la difusión pública de un discurso que reivindica lo actuado por el régimen militar.

En sus tiempos como diputado, Bolsonaro había defendido el método de la tortura por lo cual no extraña que en su voto a favor del "impeachment" contra Dilma hiciera esta declaración de principios:

Por la familia, la inocencia de los niños en las aulas, que el PT nunca tuvo, contra el comunismo, por nuestra libertad en contra del Foro de São Paulo, por la memoria del Coronel Carlos Alberto Brilhante Ustra, por el pavor de Rousseff, el ejército de Caxias, las Fuerzas Armadas, por Brasil encima de todo y por Dios por encima de todo, mi voto es sí. (“Un diputado", 2016)

Ustra fue líder del sistema de torturas que sufrieron entre tantos, Rousseff y se libró de la pena gracias a la Ley de Amnistía de 1979 que absolvió también a los militares. Tras la vuelta a la democracia, publicó el libro $A$ verdade sufocada: a história que a esquerda não quer que o Brasil conheça (Ustra, 2006). El libro presenta una versión de la dictadura desde la perspectiva de los militares, y llegó a agotarse en su $14^{\text {a }}$ edición después de que Bolsonaro afirmara que ese era su libro de referencia ("Estoy a favor", 2018).

Más recientemente, en una entrevista para el canal de TV Bandeirantes, Bolsonaro afirmó que el régimen militar tuvo "algunos problemitas", pero que no se lo puede calificar como una dictadura: "Tenemos que conocer la verdad. Ningún régimen es una maravilla. ¿Y dónde has visto a una dictadura entregar el gobierno en forma pacífica? Entonces no fue una dictadura”, sentenció el mandatario ("Bolsonaro niega", 2019). Enseguida, instó a que las principales unidades militares realizaran actos celebratorios el 31 de marzo, en conmemoración del golpe de 1964. Así, en marzo último el Comando Militar do Planalto realizó una ceremonia en la que el golpe fue rememorado como "momento cívico-militar", un eufemismo que valida la negación de calificar como dictadura al régimen de gobierno impuesto en 1964 (“Comando Militar", 2019). 
También son conocidas las declaraciones del exministro de Educación Ricardo Vélez Rodríguez, quien propuso que los libros escolares enseñaran que en 1964 no hubo un golpe de Estado perpetrado por los militares sino una "decisión soberana de la sociedad brasileña" que depuso a un presidente constitucional para establecer "un régimen democrático de fuerza" ("Cayó el ministro", 2019). Vélez es un seguidor acérrimo del escritor ultraderechista Olavo de Carvalho, famoso por sus teorías conspirativas acerca de la infiltración del marxismo cultural en las instituciones de Brasil ("Olavo de Carvalho", 2019). Actualizando la escisión maestra de la dictadura, Vélez declaró que "Brasil, durante los gobiernos del PT, estuvo al borde de quedar bajo el control de grupos totalitarios socialistas", y hoy se debe "luchar por el país donde uno vive" para que no suceda como en Venezuela que "es una colonia de los dictadores que controlan Cuba" ("Cayó el ministro", 2019). El miedo al "castro-chavismo", tiene la potencia de la sencillez al poner bajo un solo paraguas todo aquello que la derecha considera malo y oscuro sin demasiadas distinciones o explicaciones, y al mismo tiempo cumplir el objetivo de neutralizar el capital simbólico y político de la izquierda y las fuerzas progresistas, erigiéndolas como el enemigo.

Como el Gobierno de Cambiemos en Argentina, el de Bolsonaro también ha incursionado en el plano legal para garantizar la impunidad de los militares. Pero si en Argentina los intentos de instaurar leyes favorables a las FFAA no prosperaron, en Brasil iniciativas similares están avanzando. Mediante el decreto 9.759, del 11 de abril de 2019, se extinguió la Comisión de Muertos y Desaparecidos Políticos del Ministerio de la Mujer, de la Familia y de los Derechos Humanos, que tenía la misión de concluir la identificación de víctimas de la represión política durante la dictadura.

\section{Colombia: políticas del odio}

En Colombia, los procesos de paz con la insurgencia han sido el eje definitorio de las últimas tres elecciones presidenciales. En un sistema de partidos tradicionalmente inclinado a la derecha, son pocos los temas de la agenda que ofrecen matices en las propuestas programáticas en materia social o económica. El manejo del conflicto armado, por el contrario, se ha convertido en el principal punto de polarización entre los partidos y en la sociedad civil. 
Álvaro Uribe Vélez (2002-2010 y 2010-2014) supo capitalizar el rechazo generalizado hacia las acciones violentas de las FARC reduciendo el entramado de contradicciones políticas y sociales a un juego de amigos y enemigos que asumió la forma de un "nacionalismo antifariano" (López de la Roche, 2014). A través de una operación mediático-ideológica, elevó a un nivel público-político su odio personal por la insurgencia y delimitó un campo de adversidad en el que, ante el gran enemigo que eran las FARC, las masas cautivas por el discurso de la "mano firme" terminaron demandando más uniformidad ideológica, más seguridad y más orden, sin notar que desahuciaban la crítica y la oposición democráticas.

Además de los escenarios de enfrentamiento armado, la guerra declarada por el uribismo se dirimió en el plano simbólico. Junto a las FARC, fueron demonizados y declarados objetivo militar: los defensores de Derechos Humanos, líderes sociales, maestros, estudiantes y comunidades indígenas en todo el país, bajo la acusación de ser "auxiliares de la guerrilla" (CIDH, 2005). El mismo calificativo le valió al Grupo de Memoria Histórica que en 2013 publicó ¡Basta Ya! Colombia memorias de guerra y libertad, un informe sobre la violencia política ocurrida en el país desde 1958, calificado por el uribismo como un inaceptable ejercicio de manipulación histórica "basado en las hipótesis de sectores radicales" ("Mindefensa", 2013).

En paralelo discurrió la apuesta por la reescritura de la historia nacional en clave contrainsurgente, que trascendió la crítica a las memorias de las víctimas para saltar activamente a la producción de ficciones televisivas "basadas en hechos reales" donde conocidos narcotraficantes y líderes paramilitares quedan convertidos en poco menos que héroes nacionales (e.g. "El Patrón del Mal" del canal Caracol y "Tres Caínes", del Canal RCN, aliado declarado del gobierno Uribe). En esta versión del pasado, el narco-paramilitarismo es presentado como el mal necesario para poner en cintura a la guerrilla, ocultando el lado más siniestro de la Política de Seguridad Democrática: la ejecución extrajudicial de más de diez mil colombianos bajo la figura de los "falsos positivos" y la convalidación legal, política y económica del proyecto paramilitar a través de la Ley de Justicia y Paz (Rodríguez, 2016).

Cuando los escándalos de la "parapolítica" (López, 2010) y los "falsos positivos" (CorteIDH, 2018) tomaron conocimiento público, el consenso nacional en torno a la eficacia de la salida armada al conflicto se vio socavado, allanando el camino para que el presidente Juan Manuel Santos (20102014 y 2014-2018) retomara la senda del diálogo con las FARC. La actitud 
negociadora de Santos marcó un viraje importante respecto de la era Uribe, que trascendió a nivel internacional (Rodríguez, 2014). Aunque las reformas legislativas impulsadas durante su mandato fueron tímidas y de difícil concreción en los hechos, su principal aporte consistió en la firma de los Acuerdos de Paz en La Habana en 2016.

A tres años de logrados los Acuerdos, Colombia se halla lejos de voltear la página de la violencia política. A la reconversión de los conflictos en los territorios se suman las dificultades del Estado para garantizar la seguridad de los desmovilizados y de los colombianos en general, evidentes en los numerosos asesinatos de líderes sociales, defensores de derechos humanos y activistas políticos. Por su parte, los crímenes cometidos contra integrantes de las desmovilizadas FARC-EP que han sido indultados o que están en proceso de reincorporación incumplen con las garantías pactadas en La Habana y abren la puerta a la retoma de las armas.

En un movimiento pendular que va de la guerra a la paz, la opinión pública le apostó al belicismo en las últimas elecciones presidenciales. El llamado a la mano dura contra la guerrilla fue uno de los emblemas de campaña de los opositores al proceso de paz que más receptividad tuvo. Como en el inefable triunfo del No en el Plebiscito por la Paz de 2016, las críticas al diálogo liderado por Santos y la insistencia en judicializar a los ex-guerrilleros según los cánones de la justicia ordinaria inocularon en el sentido común la idea de que las FARC se convertirían de improviso en un sector beneficiado por todo tipo de dádivas estatales. En un país donde la pobreza ronda el 28\%, según estimaciones recientes de la CEPAL, la divulgación de noticias falsas acerca de los recursos ingentes que disfrutarían los guerrilleros desmovilizados en detrimento de sectores como los jubilados enardecieron el sentido de injusticia de la ciudadanía e inclinaron la balanza a favor del candidato uribista Iván Duque.

Una nueva controversia surgió bajo el gobierno de Duque (2018-), a propósito del nombramiento del historiador Rubén Acevedo como director del Centro de Memoria Histórica, dada su resistencia a reconocer la existencia del conflicto armado y su origen en la disputa por la tierra, a contramano de los testimonios de las víctimas y de lo sostenido por gran parte de la historiografía colombiana e internacional. Acevedo además afirmó que la Comisión de la Verdad "es fruto del interés político de las guerrillas por imponer una explicación justificadora de sus aventuras y crímenes en ropaje académico" y expresó su negativa a la implementación de la Jurisdic- 
ción Especial de Paz (JEP), médula jurídica de los Acuerdos de Paz con las FARC ("Polémica", 2019). El "revisionismo histórico" de Acevedo coincide con las objeciones sistemáticas que Duque y su partido, Centro Democrático, han realizado a la JEP, para obstruir la concreción del esquema de justicia transicional requerido en el postconflicto.

\section{Perú: "reconciliación nacional"}

En un contexto de colapso del Estado, crisis económica y violencia política, el régimen encabezado por Alberto Fujimori (1990-2000) operó una reconfiguración autoritaria del orden (Burt, 2009). No sin dificultades, consiguió el respaldo necesario para poner en marcha un proyecto que buscaba restaurar el orden social y político desafiado por la insurgencia armada, al tiempo que reestructurar las relaciones Estado-sociedad de acuerdo a la matriz neoliberal (Tapia,1997). En 2009, Fujimori fue condenado a 25 años de prisión por los delitos cometidos en el ejercicio del poder, entre los que cuentan dos matanzas a manos del Grupo Colina en el marco de la lucha contra la guerrilla de Sendero Luminoso.

En 2010 se creó el partido Fuerza Popular (FP), y desde ese mismo momento el relato fujimorista construido sobre el pasado reciente aparece desdoblado: por un lado, la defensa estricta de lo actuado por el dictador (considerado héroe pacificador) y por el otro, la condena de lo operado por su asesor de inteligencia Vladimiro Montesinos (responsabilizado por los múltiples casos de corrupción y las violaciones a los derechos humanos) (“Keiko", 2016).

En las elecciones de 2016 hubo dos candidaturas de derecha: Pedro Pablo Kuczynski del Partido Peruanos por el Kambio (PPK) y Keiko Fujimori de Fuerza Popular (FP). El primero venció en segunda vuelta con el 50,1\% de los votos. Enseguida, Keiko comenzó las presiones para lograr la libertad de su padre, erigido líder histórico del FP. Finalmente, en diciembre de 2017 PPK concedió el indulto, pero su figura quedó muy desgastada y en marzo de 2018 debió renunciar, envuelto en acusaciones de corrupción y en medio del descontento popular por la medida tomada a favor del dictador. No obstante, antes de su renuncia PPK alcanzó a nombrar el año 2018 (es parte de la cultura institucional de Perú dar un nombre a cada año), declarándolo “Año del Diálogo y la Reconciliación Nacional”. El concepto "reconcilia- 
ción" tuvo especial resonancia en razón del reciente indulto, una clara concesión de PPK a la retórica negacionista del fujimorismo.

A diferencia de Argentina donde sí hubo un "relato canónico", en Perú a quince años de la publicación del Informe de la CVR, los sentidos de lo ocurrido durante el conflicto armado (1980-2000) no han sido fijados. Durante el gobierno de PPK (2016-2018), las luchas memoriales se desplegaron en tres escenarios de controversia ilustrativos.

Uno de ellos fue el de las denuncias que pulularon en 2012 por apología del terrorismo, provenientes de políticos tanto del fujimorismo como del APRA, a propósito de la decisión de incluir el tema del conflicto armado en la enseñanza de la historia en el diseño curricular nacional, decisión tomada en 2004 por el Ministerio de Educación. Como resultado de tales denuncias, los textos en cuestión fueron retirados oficialmente de las escuelas. En 2012, el Congreso de la República y el Presidente del Consejo de Ministros lanzaron la iniciativa "Terrorismo nunca más", con el objetivo de "informar y crear conciencia sobre las implicancias del terrorismo en el Perú, así como fomentar los beneficios de una cultura de paz y en convivencia democrática”. En el vídeo - sugerido como material educativo - son presentados los atentados cometidos por Sendero Luminoso y el MRTA entre 1980 y el 2000, sin exponer las acciones de las Fuerzas Armadas, de los Comités de Autodefensa o de otros actores (Jave, 2018).

Otro escenario fue la revelación pública de las esterilizaciones quirúrgicas involuntarias de cientos de mujeres quechuas a partir de la puesta en marcha del Registro de Victimas de Esterilizaciones Forzadas (Reviesfo) creado bajo el gobierno de Ollanta Humala en 2016. En este marco, el negacionismo no se hizo esperar. En un discurso pretendidamente académico fue publicado La verdad de una mentira: El caso de las 300 mil esterilizaciones forzadas, un libro donde la politóloga María Cecilia Villegas, asevera que se trata de un mito creado por las organizaciones feministas en alianza con la Iglesia Católica y los sectores conservadores, para acusar al fujimorismo (Villegas, 2017).

Un tercer escenario fue el conflicto por la confección del guion y las funciones atribuidas al Lugar de la Memoria (LUM), un espacio de conmemoración pedagógico y cultural que alberga la historia de violencia ocurrida en el Perú entre 1980 y 2000. En agosto de 2017, el LUM fue acusado por la bancada fujimorista de hacer apología del terrorismo, exigiendo la renuncia de su director Guillermo Nugent, por "permitir" la exposición de la retrospectiva Resistencia Visual 1992, una reflexión sobre este año desde la 
mirada de 36 artistas gráficos, colectivos y activistas. Cabe recordar que el LUM fue inaugurado en 2015 bajo el gobierno de Humala como parte de una política estatal que buscó responder a la exigencia de las víctimas y sus familias de reconocer los hechos violentos ocurridos durante dos décadas de conflicto armado y sus consecuencias para la sociedad peruana. Los hechos son contados tal como fueron expuestos en documentos oficiales como el Informe de la Comisión de la Verdad y Reconciliación y ratificados por sentencias emitidas por el sistema de justicia.

A diferencia de Argentina y de Brasil, en Perú la fuerza de derecha más prominente que ha abonado el negacionismo no está en el poder. PPK renunció en medio de escándalos. Y si bien el fujimorismo fue la fuerza predominante en el Congreso hasta hace muy poco, este se debilitó por la decisión de la Corte Constitucional de revisar el indulto a su "héroe". Actualmente, tanto Alberto Fujimori como su hija Keiko se encuentran detenidos. Por su parte, el actual mandatario Martín Vizcarra ha dado señales de avanzar en la institucionalización de políticas de DDHH al crear el Banco de Datos Genéticos en septiembre de 2018. No obstante, en las palabras que pronunció al asumir se lee cierta voluntad de borramiento de los conflictos: "Lo que ha sucedido debe marcar el punto final de una política de odio y confrontación". La creación de un organismo especializado para la búsqueda de personas desaparecidas se sustenta pues en este marco de sentidos. Más aún, en el momento de firmarse la creación de la mencionada institución, Vizcarra aseveró: "los años de violencia que sufrimos los peruanos nos afectó a todos" ("Presidente Martín Vizcarra", 2018). Es que, en Perú, a diferencia de los otros dos casos analizados hasta aquí, la derecha se erige sobre una memoria del pasado reciente que, tal como expone el Informe de la CVR en sus conclusiones, asume que tanto el Estado como la insurgencia minaron las identidades colectivas, destruyeron las bases materiales y morales requeridas para la organización social e inocularon una cultura del miedo que aún se respira en el país (CVR, 2003).

\section{Conclusiones}

Es posible agrupar a las derechas actuales según su origen: ya sea que surgen en contraposición a experiencias progresistas previas o en continuidad con una cultura política de orientación derechista. Aquí se ha enfocado el análisis en cuatro casos que se inscriben en uno (Argentina, Brasil) y otro 
tipo (Colombia, Perú). Las luchas memoriales están en el centro de las estrategias no electorales de construcción de un "sentido común" hegemónico en los cuatro casos. En este marco, las derechas han acudido a distintas modalidades de acción que se pueden caracterizar como negacionismo estatal y negacionismo academicista (Thus, 2017).

En cuanto al negacionismo estatal, en los cuatro casos se observan explícitas prácticas a través de todas aquellas declaraciones con las que presidentes, funcionarios y congresistas pretenden relativizar, banalizar y minimizar la crueldad de lo acontecido y el sufrimiento de las víctimas. La puesta en duda del número de desaparecidos de la dictadura en Argentina tiene su análogo en la negación oficial de los casos de esterilización forzada en Perú y los falsos positivos en Colombia y la presentación de la dictadura brasileña como un mal necesario para contener la avanzada comunista.

El negacionismo estatal se complementa y nutre de un negacionismo academicista que, bajo la apariencia de un falso revisionismo histórico orientado a "contar la historia completa", busca difundir un contradiscurso legitimador de la violencia estatal ilegal e ilegítima. En los cuatro casos, esto ha sido promovido a través de diversos artefactos culturales que operan en la resemantización del pasado: libros del tipo best-seller y libros de editoriales no comerciales que imprimen a pedido, como también los formatos documentales y las ficciones de TV. En esta misma línea, se ubican las disputas por los guiones de los lugares de memoria en Perú y los debates por los contenidos de historia a enseñar en las escuelas de Perú y Brasil.

Finalmente, las luchas memoriales hacen pie en el derecho que, como se sabe, no cumple solamente un papel punitivo, sino que tiene una enorme capacidad performativa como dispositivo gestor de verdad. Cada ley o sentencia tiene el poder de afectar las estructuras narrativas de la memoria nacional, visibilizando u opacando los sentidos de Justicia para víctimas y victimarios. El intento de rehabilitación de la ley $2 \mathrm{X} 1$ en beneficio de los represores en Argentina y el indulto a Fujimori (ambos revocados); la obstrucción de la JEP en Colombia y la eliminación por decreto de la Comisión de búsqueda de desaparecidos en Brasil, son ejemplos de una modalidad jurídica de reescritura de la historia por parte de los perpetradores, en las que la Reconciliación se impone sobre la Verdad y la Justicia. En este punto, cabe marcar una diferencia clave: en los casos donde hubo enjuiciamientos significativos (Argentina y Perú) el negacionismo adopta más prominentemente la fórmula de la reconciliación, mientras que en aquellos casos donde la me- 
moria estuvo menos tejida en torno a juicios por delitos de lesa humanidad el negacionismo se asentó sobre la idea de guerra.

Con todo, en los cuatro países, el negacionismo ha articulado nuevos campos de adversidad que renuevan y perpetúan las formas de opresión que estaban en el origen de las violencias (conflictos armados y dictaduras). De manera general, todas estas prácticas impactan profundamente en el presente, reavivando odios y miedos ancestrales con fines electorales y sirven para alimentar construcciones de sentido con la aspiración de hegemonía cultural.

\section{Bibliografía}

Ansaldi, W., \& Giordano, V. (2012). La construcción del orden. Buenos Aires: Ariel (T. 2).

Burt, J.M. (2009). Violencia y autoritarismo en el Perú: bajo la sombra de Sendero y la dictadura de Fujimori. Lima: IEP- Asociación SER.

Comisión de la Verdad del Perú (CVR) (2003). Informe de la Comisión de Verdad y Reconciliación, Tomo I. Lima: CVR. Recuperado de: https://bit. ly/2J14525 (2019-05-20).

Comisión Interamericana de Derechos Humanos (CIDH) (2005). Informe anual 2005. Cap. IV Desarrollo de los Derechos Humanos en la Región. Recuperado de: https://bit.ly/2EzRcw7 (2019-05-20).

Corte Interamericana de Derechos Humanos (CorteIDH) (2018). Villamizar Durán y otros vs. Colombia. Sentencia del 20 de noviembre de 2018. Recuperado de: https://bit.ly/2EzRcw7 (2019-05-20).

Comisión Nacional de la Verdad de Brasil (CNV) (2014). Informe de la Comisión Nacional de la Verdad. 3 volúmenes. Recuperado de: https://bit. ly/2Uz2ae8 (2019-05-20).

Di Pascuale, H. (2019). Crónica de una guerra negada. Guerra revolucionaria en la Argentina. Buenos Aires: Pausa Impresores.

Crenzel, E. (2008). La historia política del Nunca Más. Buenos Aires: Editorial Siglo Veintiuno.

Eaton, K. (2014). New strategies of the Latin American Right: beyond parties and elections. En J. P. Luna, y C. Rovira Kaltwasser, The resilience of the Latin American Right (pp. 75-93). Baltimore: John Hopkins University Press.

Fernández Meijide, G., \& Leis, H. (2015). El diálogo. El encuentro que cambió nuestra visión sobre la década del 70, con colaboración de Pablo Avelluto. Buenos Aires: Sudamericana. 
Giordano, V. (2017). Las ciencias sociales y los intelectuales en la perspectiva de las derechas latinoamericanas hoy. Millcayac, 4(7), 165-179. Recuperado de: https://bit.ly/2YCGEUc (2019-05-20).

Giordano, V. (2018). Apuntes para estudiar las derechas latinoamericanas actuales. Estudios Sociales del Estado, en prensa.

Giordano, V., \& Soler, L. (2016). Editoriales, think-tanks y política. La producción y circulación de las ideas de las nuevas derechas en Argentina. Revista Paraguaya de Sociología, 147, 35-50.

Goldentul, A., \& Saferstein, E. (2019). A 43 años del golpe. La memoria y el diálogo acotado. Bordes. Revista de política, derecho y sociedad. Recuperado de: https://bit.ly/2MfsY0r (2019-05-20).

Grimson, A. (2007). Introducción. En A. Grimson (Comp.), Cultura y neoliberalismo (pp. 11-16). Buenos Aires: CLACSO.

Hinkelammert, F. (1988). Democracia y nueva derecha en América Latina. Nueva Sociedad,98, 104-115. Recuperado de: https://bit.ly/2VCw51O (2019-05-20).

Jave, I. (2018). Frente al negacionismo: la memoria tantas veces negada. Instituto de Democracia y Derechos Humanos, Pontificia Universidad Católica de Perú. Recuperado de: https://bit.ly/2Jyu98J (2019-05-20).

Jelin, E. (2002). Los trabajos de la memoria. Madrid: Siglo Veintiuno.

López de la Roche, F. (2014). Las ficciones del poder. Patriotismo, medios de comunicación y reorientación afectiva de los colombianos. Bogotá: Debate.

López, C. (2010). Y refundaron la patria. De cómo mafiosos y políticos reconfiguraron el Estado colombiano. Bogotá: Debate.

Petrella, I. (2015). Que se metan todos: El desafío de cambiar la política argentina. Buenos Aires: Sudamericana.

Ricoeur, P. (2010). La memoria, la historia, el olvido. Madrid: Editorial Trotta.

Rodríguez, G. P. (2014). Uribe y Santos: ¿la misma derecha? Nueva Sociedad, 254, 84-99. Recuperado de: https://bit.ly/2VCp9BL (2019-05-20).

Rodríguez, G. P. (2016). ¿Cesó la horrible noche? Marchas y contramarchas de la paz en Colombia. Revista Política Latinoamericana, 3. Recuperado de: https://bit.ly/2Jw8D4F (2019-05-20).

Rodríguez, G.P. (2019). Vueltas y revueltas de las derechas en el Perú a comienzos del siglo XXI. Estudios Sociales del Estado, en prensa.

Saferstein, E. (2017). La edición como intervención cultural, comercial y política: los best-sellers políticos del Director de Random House-Sudamericana durante el kirchnerismo. Millcayac, 4(7), 141-164. Recuperado de: https://bit.ly/2M2QYDP (2019-05-20). 
Tapia, C. (1997). Las Fuerzas Armadas y Sendero Luminoso. Dos estrategias y un final. Lima: IEP.

Thus, V. (2017) Los desaparecidos según Macri. Revista Espacios de Crítica y Producción, 53, 117-133. Recuperado de: https://bit.ly/30su9wi (2019-05-20).

Ustra, C.A. B. (2006). A verdade sufocada: a história que a esquerda não quer que o Brasil conheça. Brasilia: Editora Ser.

Villegas Otero, M. C. (2017). La verdad de una mentira. El caso de las 300 esterilizaciones forzadas. Lima: Planeta.

Vommaro, G., Morresi, S., \& Belloti, A. (2015). Mundo Pro. Anatomía de un partido fabricado para ganar. Buenos Aires: Planeta.

\section{Artículos de prensa}

"Bolsonaro niega el golpe de Estado de 1964 y las víctimas repudian el llamado a celebrarlo", NODAL, Noticias, 28 de marzo de 2019. Recuperado de: https://bit.ly/2JPzJ7M (2019-05-20).

“Carlotto denunció a Di Pascuale y a su panfleto negacionista". Página 12, 7 de mayo de 2019. Recuperado de: https://bit.ly/2VQs9hW (2019-05-20).

“Cayó el ministro negacionista del golpe”, Página 12, 9 de abril de 2019. Recuperado de: https://bit.ly/2I7DbZH (2019-05-20).

"El discurso PRO de los derechos humanos", Página 12, 24 de marzo de 2017. Recuperado de: https://bit.ly/2VwJyrF (2019-05-20).

"Estoy a favor de la tortura y lo sabes": Jaír Bolsonaro reabre las heridas de la dictadura. El Confidencial, 23 de octubre de 2018. Recuperado de: https:// bit.ly/2w4Joh1 (2019-05-20).

"Keiko: Yo de ninguna manera hubiera cerrado el Congreso". 2016. El Comercio, 31 de enero, Recuperado de: https://bit.ly/2YAW3og (2019-05-20).

"Mindefensa lanzó críticas al libro de Memoria Histórica". 2013. El Tiempo, 23 de septiembre, Recuperado de: https://bit.ly/30vTk1b (2019-05-20).

“Olavo de Carvalho, el 'filósofo' de Bolsonaro”. El País, 7 de enero de 2019. Recuperado de: https://bit.ly/2QhDOkL (2019-05-20).

"Polémica en Colombia por dirección del Centro de Memoria Histórica", Prensa Latina, 4 de febrero de 2019. Recuperado de: https://bit.ly/2HKq1iQ (2019-05-20).

“Un diputado brasileño dedica su voto a favor del 'impeachment' al general que torturó a Rousseff”. La Vanguardia, 18 de abril de 2016. Recuperado de: https://bit.ly/2JS988s (2019-05-20). 
"Mauricio Macri reactiva la polémica por el número de desaparecidos en Argentina". El País, 11 de agosto de 2016. Recuperado de: https://bit.ly/2QfpusW (2019-05-20).

"Comando Militar do Planalto trata golpe como 'momento cívico-militar”, Veja, 29 de marzo de 2019. Recuperado de: https://bit.ly/2Enbhpa (2019-05-20).

"Presidente Martín Vizcarra promulga decreto legislativo que crea el banco de datos genéticos", Ministerio de Justicia y Derechos Humanos, 7 de septiembre de 2018. Recuperado de: https://bit.ly/2VR8O0S (2019-05-20).

Fecha de envío: 2019/05/24; Fecha de aceptación: 2019/07/31;

Fecha de publicación: 2019/09/01 